\title{
Lessons from genetic discrimination
}

Discrimination is a fact of life. While certainly a social phenorrenon, considerable information in our genomes is devoted to it. Self versus nonself determinations, in an immunologic sense, are accomplished by highly polymorphic genes, the unique properties of their products, receptors that interact with these protein targets and the resulting biological functions. Whether by deletion, selection, tolerance, paralysis, or suppression, an enormously intricate system regulates this biblogical reaction to difference. Observations of assortative mating and neuropsychological development of children also suggest biological influences on what we consider as different.

Naturally, as with even tightly genetically regulated systems, environmental effects can substantially alter the resulting phenotypes and choices. Allogeneic cells become "self" if transplanted early in development. Children exposed to various languages, skin colors, and behaviors are probably less likely to distinguish them as different over time. Thus, it seems that difference discrimination deemed as unwanted can be ameliorated.

Historically, because of limited research methods, human geneticists often identified differences based on phenotypic criteria, and then sought genetic data to explain these observations. The preoccupation with distinguishing human variation arose from experimental necessity. It may have also fit many scientists' philosophies at the time. Most human geneticists throughout the first half of the $20^{\text {th }}$ century were eugenicists who may have viewed human difference as something to be identified, then eliminated or enhanced.

Reverse genetics and genomic technology have lessened the preoccupation with phenotypic difference. Claims voiced early in the course of the Human Genome Project (HGP) that cataloguing human genetic differences (individual; within and among groups; and among species) would provide an effective argument to eliminate forms of discrimination in our society still seem far-fetched. The data support both similarity and difference between individuals and groups. And powerful forces may be fostering discrimination, including previously mentioned biological as well as social, economic, cultural and historical factors. Scientific activity and education about its data have yet to be shown as effective in altering social problems like unwanted discrimination. The increasing sensitivity toward environmental damage and conservation by young people may be an example that refutes my skepticism.

Recognizing the historical relationship of human genetics to the description of difference, and also admitting that social institutions discriminate among customers and applicants as a matter of normal operations, genetic discrimination has been anticipated. ${ }^{1,2}$ It was, therefore, not surprising when my colleagues and I initially described contemporary examples. ${ }^{3,4}$ This work was promptly reproduced and extended indepen- dently, despite important limitations in research methods, reluctance by those who feared or experienced discrimination to be research volunteers, and little cooperation by the entities (for instance, insurance companies) that would be the best sources of data. ${ }^{5-7}$ While insurance commissioners or their employees, and members of the human genetics professional community, may differ from consumers on the importance or rate of cases of genetic discrimination, few have tried to deny its existence. Since our health care finance system is based on the discriminatory process intrinsic to insurance and the lack of privacy in medical interactions allows genetic information relevant to health to be circulated widely, some genetically based discrimination occurs more as a result of inadvertent events or ignorance rather than by design.

What has ensued from this research has been further investigation and academic/professional discussion about genetic discrimination; significant public media coverage of the issue; the inclusion of warnings about it in patient counseling, research informed consent documents, and stock investment prospectuses; and state legislation aimed at limiting its impact on insurance and employment processes of state chartered corporations. It is an understatement to note that this topic is controversial. It took several years to publish the original data. Debates followed about the proper definition of genetic discrimination, its differentiation from other forms of stigma and difference determination common in our society, and its documented association with adverse outcomes rather than salutary ones. Arguments have been voiced about whether genetic information, which can foster discrimination, is different from other forms of medical data and whether public policy about genetic discrimination should be considered as a component of larger efforts in medical and individual privacy. Though no clear resolutions have come to these controversies, the "incrementalism" that state legislation represents is an accomplishment and may have stimulated both a public debate in many legislatures and federal activity at least by the Executive Branch.

In this issue of the Joumal, Hall and Rich publish the third report of a study of genetic discrimination.." "1" Despite limitations in their methods that are not dissimilar to problems with all the other studies in this field, they provide data that are consistent with the position that genetic discrimination is not a significant problem in clinical genetics currently. In this article, they suggest that protections now in place or that may come in the future may not result in more appropriate utilization of genetic information or tests by individuals, their consultants, or third parties.

State laws certainly have had a limited impact. Almost no one knows they exist, they are not enforced and, to my knowledge, no cases have been tried using them. But the hundreds of 
individuals who have self reported experiences of genetic discrimination still require relief. And the cautious market response to genetic testing may have many determinants; data suggesting that "at risk" families avoid genetic information to lessen the possibility of genetic discrimination could be a partial explanation. 6.11

No one knows how best to lessen the adverse and invidious aspects of discrimination in our society. The Civil Rights Movement, Supreme Court decisions, legislation (state and federal), public policy like affirmative action or busing, public education, and media coverage have yet to eliminate racial discrimination in many commentators' views. The basis of discrimination is often complex, and its eradication appears to require a comprehensive approach with early education and socioeconomic interventions that may need time on a human generational scale to have an effect. Interventions must also be balanced, recognizing both the importance and proper limitation of difference determination in our society. Finally, responses to discrimination ought to arise from political and cultural activity based on basic legal tenets, like those found in the founding documents of the United States, rather than scientific data or biological explanations.

Federal legislation has successfully funded the National Center for Human Genome Research, the Department of Energy's Genome Project, and allowed the flourishing research and development effort in the private sector that has now produced a version of the sequence of the human genome. But who if anyone should own or have proprietary rights to basic DNA information? Resolving this central question and mapping a course for appropriate use of genetic data (not resulting in adverse discrimination) in health care and other sectors still require improved policies. This has been true since well before the HGP began. While public processes are often responsive rather than proactive, and work like Hall and Rich's continues to foster needed discussion, the pace of progress in human genetics and associated fields (artificial reproductive technologies; gene transfer and manipulation; transplantation) seems to require prompt public policy responses in a manner faster than we have experienced even in the recent past.

Paul R. Billings, MD, PhD Genesage, Inc:

San Francisco, California www. GeneSage.com pbillings@genesage.com

\section{References}

1. Motulsky AG. Brave new world? Science 1974;185:653-663.

2. Motulsky AG. Impact of genetic manipulation on society and medicine. Science 1983:219:135-140.

3. Billings PR, Kohn MA, de Cuevas M, Beckwith J, Alper JS, Natowicz M. Discrimination as a consequence of genetic testing. Am J Hum Genet 1992;50:476-482.

4. Billings P, Beckwith I. Genetic testing in the workplace. Trends Genet 1992;8:198202.

5. Lapham EV, Kozma C, Weiss JO. Genetic discrimination: perspectives of consumers. Science 1996;274:621-623.

6. Geller LN, Alper IS, Billings PR, Barash CI, Beckwith J, Natowicz M. Sci Eng Ethics 1996;2:71-88.

7. Wertz DC. Genetic discrimination: results of a survey of genetics professionals, primary care physicians, patients, and public. Health Law Rev 1999;7(3):7-8.

8. Hall MA. Legal rules and industry norms: the impact of laws restricting health insurers' use of genetic information. Jurimetics 1999;40:93-122.

9. Hall MA, Rich SS. Laws restricting health insurers' use of genetic information: impact on genetic discrimination. Am J Hum Genet 2000;66:293-307.

10. Hall MA, Rich SS. Patients' fear of genetic discrimination by health insurers: the impact of legal protections. Genet Med 2000;2:214-221.

11. Smith $\mathrm{K}$, Packman $\mathrm{S}$, Billings $\mathrm{P}$. Discrimination arising from genetic information [Abstract]. Clin Res 1994;42:32. 